\title{
Telemedicine in Low and Middle Income Countries: Closing or Widening the Health Inequalities Gap?
}

\author{
Abdulhammed Opeyemi Babatunde ${ }^{1,2 *}$, Abdulsobur Olatunde Abdulazeez ${ }^{1}$, Esther Abimbola Adeyemo ${ }^{1}$, \\ Christabel Ijeoma Uche-Orji ${ }^{1}$, Abdulbaasit Akinkunmi Saliyu ${ }^{1}$
}

\footnotetext{
${ }^{1}$ Department of Medicine \& Surgery, College of Medicine, University of Ibadan, Ibadan, NIGERIA

${ }^{2}$ Healthy Africans Platform, Ibadan, NIGERIA

*Corresponding Author: abdulhammedbabatunde99@gmail.com
}

Citation: Babatunde, A. O., Abdulazeez, A. O., Adeyemo, E. A., Uche-Orji, C. I. and Saliyu, A. A. (2021). Telemedicine in Low and Middle Income Countries: Closing or Widening the Health Inequalities Gap?. European Journal of Environment and Public Health, 5(2), em0075. https://doi.org/10.21601/ejeph/10777

\section{ARTICLE INFO}

Received: 26 Oct. 2020

Accepted: 19 Dec. 2020

\begin{abstract}
Telemedicine has shown potentials in salvaging the dwindling healthcare system in low and middle-income countries but faced certain challenges that may create new health inequalities especially based on income. This letter discusses the debate that arises regarding the role of telemedicine on health inequalities in low and middleincome countries (LMICs). It calls for the development of strategies to prevent the widening of the health inequalities gap in LMICs from telemedicine usage. Recommendations were also highlighted to facilitate universal health coverage in LMICs through telemedicine.
\end{abstract}

Keywords: telemedicine, health inequalities, e-health, LMICs, developing countries

Dear Editor,

All countries of the world suffer from a gap in the health status of various citizens. These health disparities are termed 'health inequalities'. Health inequalities are unfair and avoidable differences in health across the population, and between different groups within the society (National Health Service, 2020). Numerous evidences have shown that there is a clear and definite relationship between the health of individuals and their socio-economic factors. Research has shown that $87 \%$ of premature deaths due to noncommunicable diseases occur in low and middle-income countries (World Health Organization, 2017). This figure supports the differences that exist in the health status of low and middle-income countries (LMICs) and high-income countries (HICs). Health inequalities are not restricted to inequalities between continents alone, it also exists within countries. For example, in the United States of America, African Americans represent only about $13 \%$ of the population but account for almost half of all new HIV infections. (World Health Organization, 2017).

Healthcare delivery is experiencing growing technological advancement with the use of telemedicine and other technologies. Telemedicine refers to the provision of remote clinical services, via real-time two-way communication between the patient and the healthcare provider, using electronic audio and visual means (Thomas, 2018). Telemedicine allows healthcare officials to treat, examine, diagnose, and assess patients irrespective of their location using mobile phones, computers and a host of other devices (World Health Organization, 2010). However, due to certain challenges of telemedicine peculiar to low and middle-income countries, debate arises on whether telemedicine increases health inequalities or otherwise in these countries (Combi, Pozzani and Pozzi, 2016).

Generally, there are insufficient healthcare resources in the low and middle-income countries and the available ones are yet unevenly distributed due to the rural-urban divide (Bagchi, 2006). Currently, almost all African countries have an access to the internet. Precisely, 53 out of 54 African countries have internet access at least in their capital city (KamsuFoguem \& Foguem, 2014). Telemedicine being implemented in developing countries has helped to close the inequality gap as regards health care services. First, it bridges the rural-urban divide; health care services can get to the remotest places in low-income countries including specialized health services like dermatology (Bagchi, 2006). Besides, it has reduced the cost of health care service; promoted early disease detection; increased accessibility of basic health education and information; and improve the management of diseases via teleconsultation (Woodend et al., 2008). Telemedicine also provides global education and research opportunities for physicians and medical professionals in form of online courses and biomedical databases respectively (Conde et al., 2010). Also, tele-expertise allows physicians to seek a second opinion 
thereby reducing medical errors (Dharmar et al., 2013; KamsuFoguem \& Foguem, 2014). Lastly, home-based health care services are made possible by telemedicine especially geriatrics medicine and chronic disease management (Gagnon et al., 2006). Some of the new developments in Africa include Frontline SMS by Medic mobile in Mali, MDNet by Vodafone Ghana in Ghana, Weltel in Kenya, WE CARE in Nigeria and Africa teledermatology project in Botswana (Kamsu-Foguem and Foguem, 2014). Many ways telemedicine has reduced health care inequalities between developing and developed countries as well as within developing countries cannot be overemphasized.

Various opportunities of telemedicine stated showed its potentials in salvaging the dwindling healthcare system in low and middle-income countries (LMICs) (Latulippe et al., 2017). However, the reverse might be the case considering some of the local challenges facing telemedicine in these countries and regions. Although telemedicine has been proven to improve health care delivery of users even in LMICs preexisting socioeconomic disparities within the population of LMICs may widen health inequalities between users and nonusers of telemedicine services (Latulippe et al., 2017). LMICs are characterized by a wide gap between the high-income earners and low-income earners with the latter constituting the larger percentage of the population. The disparity in these challenges denies particular population access to telemedicine services based on income, ethnicity, literacy, and others.

Most telemedicine services (eHealth) require access to a good internet connection preferably $4 \mathrm{G}$ therefore creating new health inequalities (Neter and Brainin, 2012). However, it was estimated that only $35 \%$ of residents in developing countries have access to the internet with some poor countries like Guinea, Somalia, Burundi, and Eritrea having lower than 2\% internet coverage (United Nations, 2015). Besides, the cost of internet subscription is relatively higher in LMICs compared to developed countries. For example, an average citizen in Africa will spend about $18 \%$ of monthly income to purchase $1 \mathrm{~GB}$ data compared to $1 \%$ for an average European citizen (Alliance for Affordable Internet, 2017). Despite promising impacts of mHealth in improving outpatient management especially for chronic diseases, a significant percentage of the population in LMIC still lack access to mobile phones that are sophisticated enough to access these mHealth services. Although the rate of mobile coverage is high in many African countries but the growth of unique subscribers is relatively lower. Hence, a large population group will consistently lack access to mobile phones and consequently mHealth services while the smaller population benefit from numerous opportunities offered by mHealth services including virtual consultations, diagnostic tests, and prescriptions of drugs. Therefore, further widens the health inequality in the community.

Besides, the internet is widely dominated by very few languages of the world notably English and French. This disparity in language influences accesses to online health information, virtual consultation, and communication among health workers globally. Developing countries have a low literacy rate. Therefore, numerous telemedicine services in foreign languages may exclude a significant proportion of population with proficiency only in native language from accessing such health services.
Furthermore, telemedicine services are easier and costeffective to use and establish compared to physical health services (Latulippe et al., 2017). Medical graduates in developing countries may prefer to establish a telemedicine startup rather than working or establishing a hospital in the community. Telemedicine may also facilitate medical migration due to the general perception that local communities can still be catered for remotely through different telemedicine innovations like telesurgery, teleauscultation, teleradiology, and others. Hence, worsen the shortage of health workforce thereby denying some communities access to qualified doctors and promote overcrowding in a few equipped health facilities locally.

Another shortcoming of telemedicine which may widen health inequalities in developing country is that most telemedicine services focus on chronic and noncommunicable diseases relating to dermatology, cardiology, wound care amongst others (Hersh et al., 2006). Although, non-communicable diseases are the major global health concern of the 21st century, infectious diseases are still the leading causes of deaths in low and middle-income countries especially rural areas with poor hygiene and sanitation (Mathers et al., 2017).

\section{RECOMMENDATIONS AND CONCLUSION}

There is a need to increase the knowledge and awareness of local communities about the benefits of telemedicine services over traditional health services. Aside from procurement and availability of evenly distributed infrastructures, the design process for telemedicine innovations should include community engagement of prospective users (Marchang, 2014). This should include effective collaborations with community leaders, health professionals, academic institutions and educators, health administrators, and policy-makers in the locality to ascertain the societal needs. (World Health Organization, 2010). Also, funding for innovations to improve healthcare should not only focus on technological innovations but also on social innovations (Marchang, 2014). Training on digital literacy is highly important together with developing telemedicine initiatives compatible with native languages will help reduce existing health inequalities based on the level of literacy. Telemedicine services should consider the inclusion of the disabled in reducing reduce health inequalities.

In conclusion, telemedicine has the potential to reduce health inequalities and facilitate the achievement of universal health coverage in low and middle-income countries. However, telemedicine innovations in the future should be more human-centered to cater for the realities in low and middle income countries.

\section{REFERENCES}

Alliance for Affordable Internet (2017). A4AI calculations based on ITU pricing data (2013-2015).

Bagchi, S. (2006). Telemedicine in rural India. PLoS medicine, 3(3), e82. https://doi.org/10.1371/journal.pmed.0030082 
Combi, C., Pozzani, G. and Pozzi, G. (2016). Telemedicine for Developing Countries. Appl Clin Inform, 7(4), 1025-1050. https://doi.org/104338/ACI-2016-06-R-0089

Conde, J. G., De, S., Hall, R. W., Johansen, E., Meglan, D. and Peng, G. C. (2010). Telehealth innovations in health education and training. Telemedicine journal and e-health, 16(1), 103-106. https://doi.org/10.1089/tmj.2009.0152

Dharmar, M., Romano, P. S., Kuppermann, N., et al. (2013). Impact of critical care telemedicine consultations on children in rural emergency departments. Critical care medicine, 41(10), 2388-2395. https://doi.org/10.1097/ CCM.0b013e31828e9824

Gagnon, M. P., Duplantie, J., Fortin, J. P. and Landry, R. (2006). Implementing telehealth to support medical practice in rural/remote regions: what are the conditions for success?. Implementation science, 1, 18. https://doi.org/10.1186/ 1748-5908-1-18

Hersh, W. R., Hickam, D. H., Severance, S. M., Dana, T. L., Krages, K. P. and Helfand, M. (2006). Diagnosis, access and outcomes: update of a systematic review of telemedicine services. Journal of Telemedicine and Telecare, 12(2_suppl), 3-31. https://doi.org/10.1258\%2F135763306778393117

Kamsu-Foguem, B., and Foguem, C. (2014). Telemedicine and mobile health with integrative medicine in developing countries. Health Policy and Technology, 3(4), 264-271. https://doi.org/10.1016/j.hlpt.2014.08.008

Latulippe, K., Hamel, C. and Giroux, D. (2017). Social Health Inequalities and eHealth: A Literature Review with Qualitative Synthesis of Theoretical and Empirical Studies. J Med Internet Res., 19(4), e136. https://doi.org/10.2196/ jmir.6731

Marschang, S. (2014, 21 February). Health inequalities and e health: report of the health stake holder group. European Public Health Alliance (EPHA).
Mathers, C., Stevens, G., Hogan, D., et al (2017). Global and Regional Causes of Death: Patterns and Trends, 2000-15. In: Jamison, D.T., Gelband, H., Horton, S., et al., editors. Disease Control Priorities: Improving Health and Reducing Poverty. 3rd edition. Washington (DC): The International Bank for Reconstruction and Development/The World Bank; Chapter 4. https://doi.org/10.1596/978-1-46480527-1_ch4

National Health Service (NHS) (2020). Definitions for Health Inequalities. NHS United Kingdom. Available at: https://www.england.nhs.uk/ltphimenu/definitions-forhealth-inequalities/ (Accessed: 20 October 2020).

Neter, E. and Brainin, E. (2012). eHealth literacy: Extending the digital divide to the realm of health information. Journal of medical internet research, 14(1), e19. https://doi.org/10.2196/jmir.1619

Thomas, L. (2018, August 23). What is Telemedicine? Available at: https://www.news-medical.net/health/What-isTelemedicine.aspx_(Accessed: 18 October 2020).

United Nations (2015). Billions of people in developing world still without internet access, new UN report finds. UN News. Available at: https://news.un.org/en/story/2015/09/509292 -billions-of-people-in-developing-world-still-without-int ernet-access-new-un-report (Accessed: 20 October 2020).

Woodend, A. K., Sherrard, H., Fraser, M., Stuewe, L., Cheung, T. and Struthers, C. (2008). Telehome monitoring in patients with cardiac disease who are at high risk of readmission. Journal of critical care, 37(1), 36-45. https://doi.org/10.1016/j.hrtlng.2007.04.004

World Health Organization (2010). Telemedicine opportunities and development in member state. Global eHealth Review Series, Volume 2. Available at: https://apps.who.int/iris/bitstream/handle/10665/44497/9 789241564144_eng.pdf?sequence=1

World Health Organization (2017). 10 facts on health inequities and their causes. Available at: https://www.who.int/ features/factfiles/health_inequities/en/ (Accessed: 18 October 2020). 